\title{
A Survey on College English Writing in China: A Cultural Perspective
}

\author{
Junhong Ren ${ }^{1} \&$ Na Wang ${ }^{1}$ \\ ${ }^{1}$ School of Foreign Languages, North China Electric Power University, Baoding, China \\ Correspondence: Junhong Ren, School of Foreign Languages, North China Electric Power University, Mailbox \\ 213, No. 689 Huadian Road, Baoding 071003, Hebei Province, China. Tel: 86-157-1250-6731. E-mail: \\ rjh1003@126.com
}

Received: October 14, $2014 \quad$ Accepted: November 15, $2014 \quad$ Online Published: December 17, 2014
$\begin{aligned} & \text { doi:10.5539/elt.v8n1p21 URL: http://dx.doi.org/10.5539/elt.v8n1p21 }\end{aligned}$

\begin{abstract}
This survey investigates to what degree the Chinese learners know about the discrepancies between Chinese and English thought patterns and their possible effects on English writing. Eighty-one students from North China Electric Power University participate in the survey. Qualitative and quantities approaches, involving the adoption of both questionnaire and data analysis, underpin the survey. Questionnaire is used to examine five constructs, namely, students' writing condition, students' knowledge about discrepancies of the Chinese and English thought patterns and their effect on Chinese learners' English writing in terms of wording, sentence structure and discourse organization. Data collected from the questionnaires are then analyzed. Findings from the study reveal that a vast majority of Chinese students are surprisingly not fully aware of the important influence thought patterns exert on languages and how discrepancies in thought patterns are associated with differences in languages. As a consequence of this, their English essays preserve some features of Chinese despite years of English learning. The results of the study contribute to a good understanding of the Chinese learners' current writing condition in EFL teaching. Suggestions to alter this undesirable situation are put forward.
\end{abstract}

Keywords: college English writing, discrepancies, Chinese and English thought patterns

\section{Introduction}

College English writing is currently receiving an increasing amount of attention in the literature on second language teaching. Numerous studies conducted by scholars both at home and abroad (Lin, 1996; Wang, 2000; Yuan \& Zhai, 2001; Gui, 2004; Ma, 2004, etc.) have shown that English writing can, to a large extent, help enhance students' comprehensive English abilities. On the other hand, however, English writing has been a thorny problem in college English teaching for long. This issue has aroused many scholars' concern. In order to solve this problem, many scholars have conducted varied research on College English writing in China. This is especially true when, along with the introduction of overseas theories and methodologies in writing (Silva \& Matsuda, 2001; Hyland, 2002; Atkinson, 2003), a growing body of research has had College English writing as their focus, their research topics covering students' writing strategies, teaching factors, language factors, writing environment and teaching reflection.

Of all the topics mentioned above, we are especially interested in the impact of the discrepancies of the Chinese and English modes of thinking on Chinese students' English writing. Researchers have now come to the consensus that Chinese has an important role to play in English writing (Guo \& Liu, 1997; Wen \& Guo, 1998; Ma \& Wen, 1999; Wang \& Wen, 2002) and that inadequate knowledge of the discrepancies of the Chinese and English thought patterns is one of the major factors that have prevented Chinese students to write idiomatic English essays (Wang \& Liu, 2001; Liu \& Deng, 2005; Li, 2005). However, while a number of studies related to the present research have been undertaken in the past, the focus of this earlier work was based predominately on theoretical analysis. Wang and Liu (2001) analyzed various drawbacks in the College English writing due to the negative transfer of the Chinese thought pattern in an effort to have the students aware of these discrepancies so as to model on the English thought pattern and compose idiomatic English writings. Liu and Deng (2005) conducted a contrastive analysis of the thought patterns of both Chinese and English, pointing out the effects these differences have on students' English writing. Li (2005) analyzed from two aspects, i.e. the circular and linear perspectives and hypotactic and paratactic perspectives of thought patterns, these discrepancies produce on the discourse organization of College students' English writings and proposed that knowledge about the differences between the Chinese and western thought patterns should be imparted to students so that students 
could be better helped to organize their compositions on the English discourse patterns and compose idiomatic English writings.

Undoubtedly, these studies contribute to better understandings of the topic under discussion, yet they fail to systematically investigate the students' knowledge about the differences in the Chinese and English thought patterns and their effects on students' English writing. Arguably, there remains a need to incorporate a qualitative approach to examine the students' learning on English writing from the perspective of the Chinese and English modes of thinking. This present study differs from the previous work to the extent that it provides more evidence covering both questionnaires and data analysis to learn about students' English writing. The results of this study may therefore be of benefit to EFL writing by enabling the teachers and researchers to better understand the current situation.

The primary purpose of this study is to, on the basis of a survey on learners' understanding of the differences between the Chinese and English thought patterns and their current College English writing condition, explore to what degree the learners know how these discrepancies affect students' writing in terms of choice of vocabulary, sentence structure and discourse development. The study also aims to put forth proposals to raise learners' awareness of these differences and improve students' English writing.

This article continues with a discussion on the major problems in College English writing teaching. The following section reviews some major points on the discrepancies of the Chinese and English modes of thinking and their effects on Chinese learners' College English writing. Gaps in previous studies are subsequently identified and the research questions are raised for investigation. Then comes the methodological approach adopted in the study. The major research instruments - a survey and data analysis, are identified. Key findings from an analysis of the research data and a detailed account and interpretation of the findings of the study with reference to each of the research questions are presented. The last section provides some places where proposals could be offered to help students write idiomatic English essays.

\section{College English Writing and Discrepancies of the Chinese and Western Thought Patterns}

\subsection{Major Problems in College English Writing Teaching}

At present, our College English Writing teaching has met with some major problems. To begin with, our College English teaching is test oriented. As a consequence of this evaluation system, many students are eager for quick success in preparing for sorts of English tests and unwilling to invest more energy or time to improve their English writing levels. To make things worse, multiple-choice items account for a major part of our English tests, which makes it impossible to effectively measure the learners' language levels. Such an evaluation mechanism is not conducive to teaching English writing and to cultivating the students' writing ability.

In addition, many teachers do not give due emphasis on College English writing. Some of them seldom teach English writing in class because of the tight course arrangement. Others are reluctant to teach students how to write in English because it is time-consuming and not productive. Still others have no clear idea the most effective ways to help improve the students' writing levels. These facts, and together with many others, are turning out a group of students who gradually diminish their motivation to improve their English writing, and give up their English study altogether in the end.

\subsection{Languages and Discrepancies of Thought Patterns}

Language and thought patterns are closely related. For one thing, language is believed to be a medium to communicate thoughts; hence different languages are thought to express our unique ways of understanding the world. For another, thought patterns are held to be the underlying mechanism of language generation and development and reflect themselves in a certain language form. Discrepancies in the thought patterns are consequently viewed to be a main reason for differences between languages (Lian, 2002).

The Chinese and the Westerners differ greatly in terms of thought patterns and these differences in thought patterns are reflected in Chinese and English languages. Generally speaking, the Chinese tend to see the world in terms of relationships. They focus their attention on interaction between man and man. In consequence, the way, the way to live and behave, not the discovery of truth, has been the goal of our philosophy. The westerners are more inclined to view the world in terms of static objects that can be grouped into categories. (Nisbett, 2004, p. 162) They attach great importance to science and technology. They systematically speculate about the nature of the universe, about the cosmos and their relationship to it. (Lamm, 1996, p. 62) Pursuit of objective knowledge of the world, in which we live, consequently, has been their mission. These discrepancies give rise to many other differences in thought patterns and ultimately differences between Chinese and English in aspects of wording, sentence structures and discourse organization. 


\subsubsection{Wording and Discrepancies of the Chinese and English Thought Patterns}

Words, to a large extent, reflect our perception of the world we are in. Due to the differences in environment and life experiences, people develop different ways of expressing the same notion. One case in point is that in English as strong as a horse is used to describe a person who has a lot of physical power to lift heavy weights, do hard physical work, etc. In Chinese, however, cow would be used to describe a person who is strong built.

Besides, in Chinese, verbs are frequently used, while in English, a great number of abstract nouns and prepositions are massively used (Yuan, 1996). That accounts for why a vast majority of Chinese learners are more likely to use The book is too difficult for me to read more than the simple yet idiomatic The book is above/ beyond me when expressing the idea that they have a hard time understanding a book.

Furthermore, the Chinese like to use modifiers as intensifiers to seek sympathy from the readers. However, the westerners are very careful in using modifiers since their major objective is to convince people through logical reasoning. This has to do with the fact that the Chinese value relationship while westerners regard the truth as the most important ( $\mathrm{Wu}, 1989)$.

\subsubsection{Sentence Structure and Discrepancies of the Chinese and Western Thought Patterns}

Great differences exist between Chinese and English in terms of sentence structure. Generally speaking, the Chinese language mainly relies on changes in word order, context and illocutionary facts and logic to achieve clarity of thoughts. English language, however, places emphasis on temporal changes and morphological changes, and depends heavily on connectives (e.g., if, however, etc.) to explain the relationship between sentence elements, sentences and paragraphs. These differences have to do with the fact the Chinese lay emphasis on psychological space in philosophy, understanding things through wuxing while the westerners devote particular care to natural space, exploring the world through logical reasoning and empirical research.

Besides, pronouns are heavily used as the subject of a sentence in Chinese. Because of this, pronouns like I/we and structures like we think, I estimate (the idiomatic way would be it can be argued that..., it is estimated that...) frequently occur in writing. In English writing more emphasis is put on facts, figures and consequently written English often goes with an impersonal style in which the speakers do not refer directly to himself or his readers, but avoid the pronouns I, you, we. This is primarily because of the different stands the Chinese and the westerner take in viewing things. To be specific, the Chinese observe the Confucian human-centered philosophy, explaining and evaluating the objective world with man as the starting point. The westerners, on the contrary, struggle to explain the world as it is. Because of this, they pay much attention to the objective things and phenomena and their influence on human beings (Leech \& Svartvik, 1974).

\subsubsection{Discourse Organization and Discrepancies of the Chinese and Western Thought Patterns}

One characteristic of writing in English is that it is virtually based on a deductive thought pattern. In this pattern, one would usually follow an overall general-to-specific sequence, in this way, the ideas consistently progress in a more or less linear order. The Chinese, however, are more likely to employ an inductive, non-linear approach to writing which involves mainly a specific-to-general sequence and circular style (Kaplan, 1966). This difference can be clearly shown by the fact that in English writing a topic sentence which may indicate an attitude/opinion is commonly presented before supporting details (e.g. reasons, conditions, facts, etc.) while in Chinese writing reasons/conditions/facts are usually positioned before attitudes/opinions/conclusions. The underlying reason for this language difference may be that the westerners, the advocators of individualism, tend to express their ideas in a direct way while the Chinese, influenced by our conservative ideology and approaches to scholarship preached in the classical doctrines, are prone to express their opinions in a roundabout manner.

\section{A Survey on College English Writing in China}

As is stated, systematic investigation of the students' knowledge about the differences in the Chinese and western thought patterns and their effects on students' English writing was largely ignored. To write an idiomatic English essay, it is essential that Chinese learners understand the English modes of thinking. To get a clearer picture of students' English writing, there seems to be a need to incorporate a qualitative approach to examine the students' learning on the English writing from the perspective of the Chinese and Western thought patterns. Hence, the authors of this article conduct this survey in an effort to enrich our knowledge of the problem under discussion.

\subsection{Study Questions}

The three main research questions involved in this study are as follows:

1) How much do the students know about the discrepancies of the Chinese and Western thought patterns? 
2) To what degree are the students aware that these discrepancies affect their English writing?

3) What should be done to raise their awareness of differences in thought patterns so as to encourage them to write idiomatic English essays?

\subsection{Participants}

The participants of this study are eighty-one EFL learners from three different majors (namely, electrical engineering, power engineering and mechanical engineering) in North China Electric Power University. Their ages ranges from 17 to 21. Most of them have learned English for at least seven years when the survey is conducted during the second semester of their first-year college learning. Of all the students participating in the study, female and male learners account for $12.05 \%$ and $87.95 \%$ of the population respectively.

\subsection{Instrument}

In this study, Questionnaire is the only investigating tool. The questionnaire is a modified survey on students' knowledge of Chinese and Western thought patterns and their effect on English writing from a professional online questionnaire platform. It consists of 15 items, with each item given three choices marked A, B and C. These items are designed to measure five constructs: learners' understanding of the differences between Chinese and English thought patterns (items $2 \& 4$ ), students' writing condition (items 1 \& 5), learners' understanding of the impact of these discrepancies on writing in terms of choice of vocabulary (items $6 \& 7$ ), sentence structure (items 8-12 \& 15) and discourse organization (items $13 \& 14$ ). Of all the items, items 11,13 and 14 are designed to learn about to what degree students learn about the impact of westerners' straightforwardness on English writing, as is stated in Choice A, item 4. Items 6, 8, 9, 12 are presented to investigated students' knowledge about what is stated in Choice B, item 4. Item 10 is posed to find out the learners' ideas on Choice C, item 4. The items are organized in such a way that students' overall understanding about the issue in discussion could be investigated. Students are required to choose the alternatives suitable for their own condition.

\subsection{Process}

The questionnaire was handed out to the students. The students were asked to finish the questionnaire in class without being informed ahead of time. In order to make sure that the students respond to the questionnaire conscientiously, the questionnaire was filled out during normal class time. We were there to provide help to those who may have difficulty understanding the items on the questionnaire. The students finished answering the questionnaire independently without negotiating with one another. The questionnaire took about 15 minutes.

\subsection{Data and Result Analysis}

\subsubsection{Data Analysis}

We collected the questionnaires, entered the data collected from the questionnaire into Excel and examined for percentages of students' choices in answering the 15 items since the percentage of each option can give us a hint on students' College English writing in China. Also we used some figures in bar charts to present the results of each construct in the hope that students' overall understanding on the discrepancies between thought patterns and their effects on English writing could be better displayed. The data provided some useful insights into how to improve College English writing in China.

\subsubsection{Result Analysis}

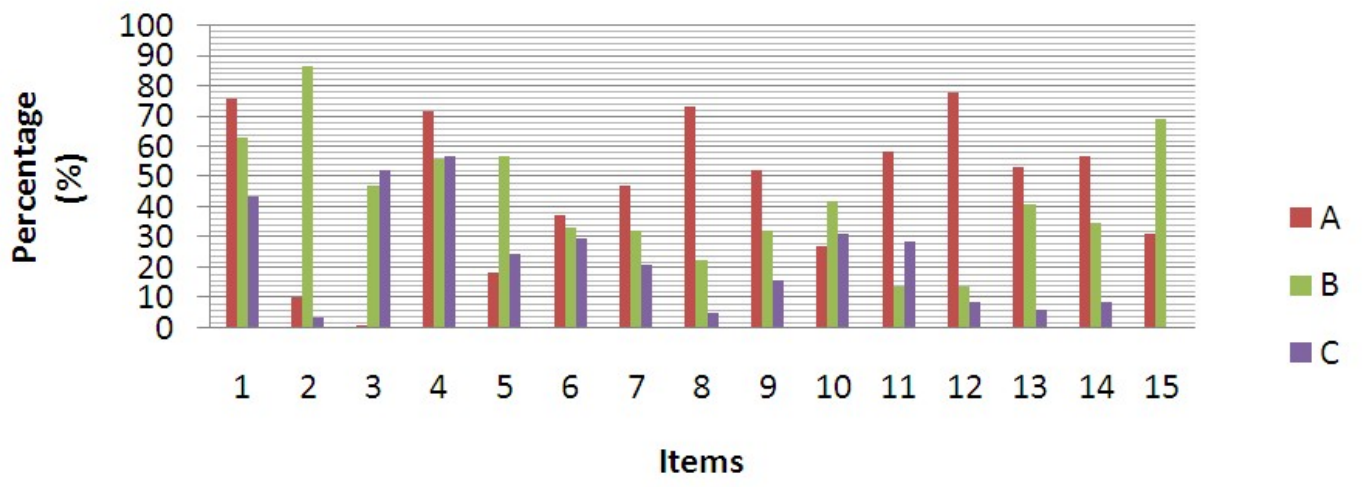

Figure 1. Questionnaire result 
From Figure 1, an overwhelmingly large number (nearly 90\%) of the respondents claim to have come to realize the differences between Chinese and the English thought patterns and important influences these differences exert on English writing. Nonetheless, their knowledge of these differences is incomplete and therefore misunderstandings can easily be spotted from their answers to the questions in the questionnaire. The following are the discussions from the five constructs.

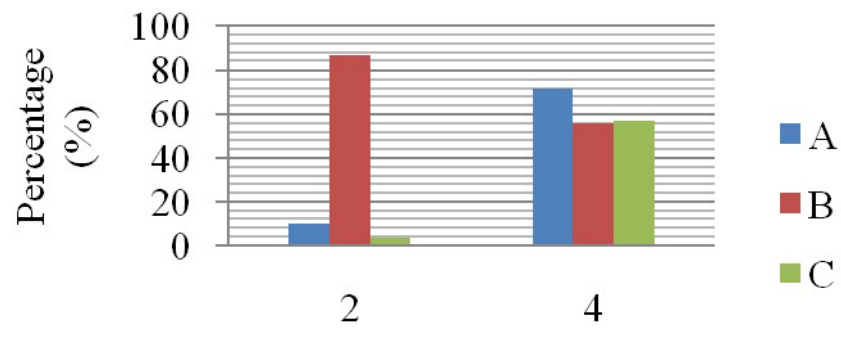

Items

Figure 2. Students' understanding of differences in thought patterns

Figure 2 shows most respondents admit having learned a little about differences between Chinese and English thought patterns. However, while a vast majority (71.6\% of the population) knows about the westerners' straightforwardness and the Chinese' indirectness, more than half of the respondents are totally ignorant of the fact that westerners tend to put emphasis on facts and rational thoughts while the Chinese are liable to adopt a subjective attitude toward the world.

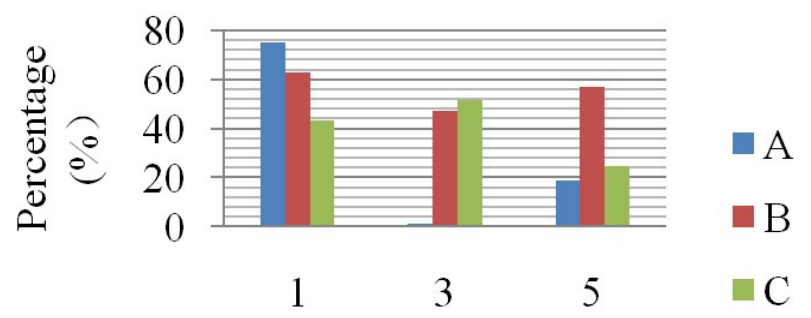

Items

Figure 3. Students' English writing

As is depicted in Figure 3, wording is the most difficult part of English writing, followed by sentence structure. Over half of the respondents write down the outline in Chinese before translating it into English in English writing, which reveals the fact that mother language still has an important impact on their English writing despite years of English study.

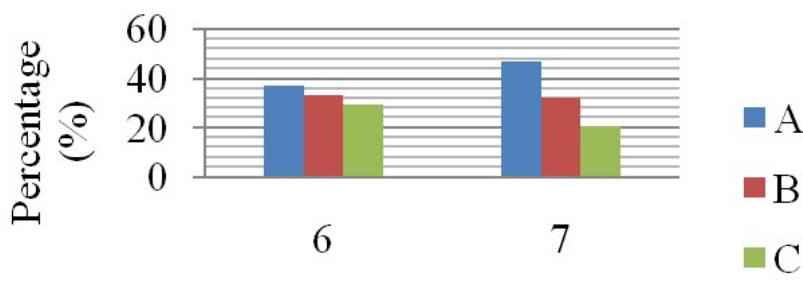

Items

Figure 4. Thought patten influence on writing in wording 
Figure 4 indicates learners' understanding of the impact of these discrepancies on writing in terms of wording. Over a third of the respondents like to use a lot of modifiers to describe things in English writing, which shows the negative transfer of mother language to their English writing. About half of the respondents choose choice A in Item 7, which indicates the fact that they have been aware of the cultural aspects of English learning.

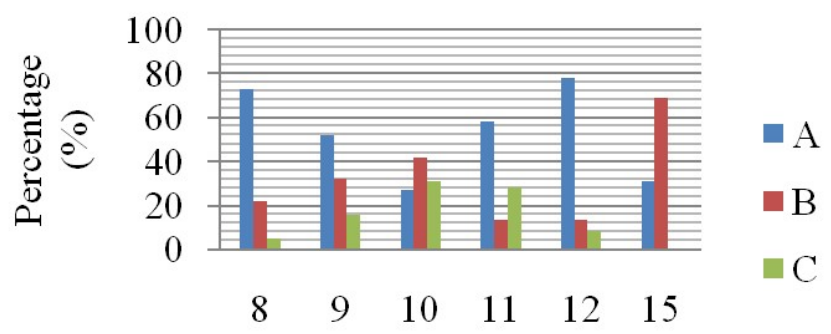

Items

Figure 5. Thought patten influence on writing in sentence structures

Figure 5 describes learners' understanding of the impact these discrepancies produce on writing in terms of sentence structure. A majority of respondents choose choice A in items 8, 9 and 12 respectively. This suggests that Chinese learners would, more often than not, use pronouns as the subject of a sentence. About 50\% of the respondents have not paid enough attention to the logic between sentences and fail to use connectives in English writing accordingly. From items 11 and 15, it can be clearly seen that over half of the respondents have been used to place the main components at the beginning of a sentence and supplement information in the residue. Sadly to notice, however, nearly $30 \%$ of the students are totally ignorant of how to organize sentence constituents in English.

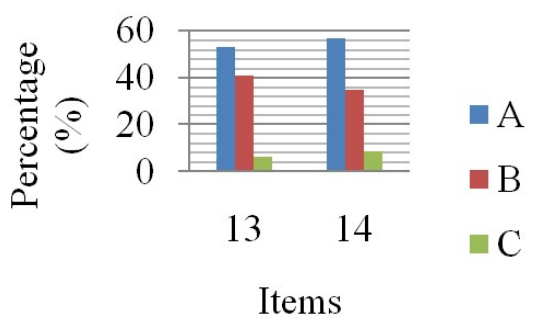

Figure 6. Thought patten influence on writing in discourse

Factor 6 illustrates learners' understanding of the impact of these discrepancies on writing in terms of discourse organization. Over $91 \%$ of the respondents have realized the way to organize ideas in English at discourse level. However, only over half of the students make conscious efforts to organize English essays in the way that attitudes/ opinions/ conclusions are followed by reasons/ conditions/facts. These figures reveal that nearly $40 \%$ of those who have become aware of the English ways of organizing ideas at discourse level still fail to follow these ways in their English writing practice.

\section{Conclusions}

From the survey, we may make some findings:

1) Contrary to their belief, a large majority of students are not aware of the important influence the differences in thought patterns exert on their English writing. Although many students make conscious efforts to model themselves on the English ways of thinking in an effort to write idiomatic English, most of them do not pay enough attention to why they have to write that way, consequently, their English is affected by the negative transfer of mother language from time to time. To illustrate, although some students choose choice B for Item 8 , they choose choice A instead of choice B for Item 9 since the two questions are of the same type aiming to check whether students learn about the fact that Chinese tend to use pronouns as the subject of a sentence while written English often goes with an impersonal style in which the speakers do not refer directly to himself or his readers, 
but avoid the pronouns I, you, we.

2) Students lack systematic knowledge of differences between the Chinese and English thought patterns and how these patterns are reflected in languages. To illustrate, although a majority of students claim to learn about the westerners' straightforwardness (choice A, item4,), a large number of them are ignorant of how the westerners' straightforwardness is reflected in English, and that accounts for why there are large disparities between the number of respondents who choose choice A in Item 4 and those who choose choices A for Items 11, 13 and 14 respectively. The same is true of the number of those who choose choice B for Item 4 and those who choose choice B for Items $6,8,9$ and 12 respectively. These facts convey to us the message that students have no sufficient knowledge about how a thought pattern is reflected in a language, or why they have to express their ideas in English in a way that is different from their own.

It can be inferred from the survey that cultural aspects of English learning should be enhanced, among which systematic study of differences between the western and the eastern thought patterns is badly needed in College English writing. Being ignorant or incomplete knowledge of these differences has now hindered the students from moving forward in their English writing.

To alter this undesirable situation, it is strongly recommended that teachers teach writing based on reading, as the westerners' thought pattern could be perfectly embodied in the original reading materials. If the teachers could teach writing while reading and explore the elements that can best display the differences in thought patterns, students will not only have a taste of these cultural differences but also imitate in a more effective way before creating their own essays than otherwise be blinded from these facts. In this way, it can be expected that students will benefit from these teaching activities and grow up to be efficient English learners.

\section{References}

Atkinson, D. (2003). L2 Writing in the Post-process Era: Introduction. Journal of Second Language Writing, 3-15.

Guo, C., \& Wen, Q. (1997). A Dynamic Research into L1 Influence on L2 Writing. Modern Foreign Languages, 4, 30-38.

Guo, C., \& Wen, Q. (1998). The Relationship between Thinking in L1 and L2 Writing Ability: A Study of the Process of English Picture Composition by Senior Middle School Students. Modern Foreign Languages, 4, 44-56.

Hyland, K. (2002). Teaching and Researching Writing. New York: Longman.

Lamn, R. C. (1996). The Humanities in Western Culture (4th ed.). London: Brown \& Benchmark Publishers.

Leech, G., \& Svartvik, J. (1974). A Communicative Grammar of English (p. 25). Longman.

Li, S. (2005). The Impact of Discrepancies of the Oriental and Occidental Modes of Thinking on the Discourse Organization of College English writing. Foreign Language Education, 26(2), 52-56.

Lian, S. (2010). Contrastive Studies of English and Chinese. Beijing: Higher Education Press.

Liu, H., \& Deng, L. (2005). The Influences of Differences of Chinese and English Thinking Modes on College English Writing. Journal of Xi' an International Studies University, 13(1), 78-80.

Ma, G., \& Wen, Q. (1999). The Relationship of L2 Learners' Linguistic Variables to L2 Writing Ability. Foreign Language Teaching and Research, 4, 321-326.

Nisbett, R. E. (2004). The Geography of Thought. New York and London: Free Press.

Silva, T., \& Matsuda, P. K. (Eds.). (2001). Landmarks Essays on ESL Writing. Mahwah, NJ: Lawrence Erlbaum Associates.

Wang, L., \& Wen, Q. (2004). Influences of L1 Literacy on L2 Writing: A Study of Chinese Tertiary EFL Learners. Foreign Language Teaching and Research, 3, 205-212.

Wang, P., \& Liu, W. (2001). Discrepancies of the Oriental and Occidental Modes of Thinking and College English Writing. Foreign Language World, 85, 66-72.

Wang, W., \& Wen, Q. (2002). An Investigation into L1 use in the L2 Writing Process of Tertiary-Level English Learners in China. Journal of PIA University of Foreign Languages, 4, 64-76.

Wu, S. (1989). Understanding Chinese Culture from Psychological Distance. In Y. Yu (Ed.), Similarities and Differences between Chinese and Western Culture (p. 56). Beijing: New Sanlian Press. 
Yuan, C. (1996). Comparison and Translation between English and Chinese Figures of Speech. In M. Fang, \& B. Ma (Eds.), Chinese-English Translation Practice and Skills (pp. 60-69).

\section{Appendix A}

A Questionnaire about the Chinese and English Thought Patterns and College English Writing

Gender: male ( ) female ( )

Age

Major

English learning experience years

The following questions are about your understanding of the differences between the Chinese and the western thought patterns and their effects on English writing, choose what you think is(are) the proper answer(s).

1. What do you think are the difficult aspects of English writing?

A. choice of vocabulary

B. sentence patterns

C. organization of discourse

2. How much do you know about the discrepancies between the Chinese and English modes of thinking?

A. I am totally ignorant of it.

B. I know just a little about it.

C. I know well about it.

3. To what extent do you think the discrepancies between the Chinese and English modes of thinking affect your English writing?

A. They have no effect on my English writing.

B. They have some effect on my English writing.

C. They have great effect on my English writing.

4. What do you think are the discrepancies between the Chinese and English modes of thinking?

A. The westerners tend to be straightforward while the Chinese are inclined to be reserved owing to the influences of Confucianism, Taoism, and Buddhism.

B. The westerners give emphasis to facts and pay much attention to accuracy and concreteness when describing things while the Chinese are more likely to be subjective and are more liable to idealism.

C. The westerners are good at logical thinking and scientific analysis, and tend to resort to abstract concepts in reasoning while the Chinese tend to combine theory with emotion in working a problem out.

5. How often do you write down the outline in Chinese before translating it into English in writing?

A. Quite often.

B. Sometimes.

C. Never.

6. Do you use a lot of adjectives to describe a thing in English writing?
A. Yes.
B. No.
C. Uncertain.

7. Which phrase do you think is an idiomatic expression in English?

A. as strong as a horse

B. as strong as a cow

C. as strong as a tiger

8. Which comes to you first when you want to express the idea that you could not recall her name?

A. I can't remember her name.

B. Her name escaped me. 


\section{Other}

9. How do you usually express the idea when the passage you are reading is too difficult for you?

A. This passage is too difficult for me to read.

B. This passage is beyond me.

C. Other

10. Do you usually ignore the logic between sentences and seldom use connectives in English writing?
A. Yes
B. No
C. Uncertain

11. What do you usually do when writing a sentence in English?
A. Main components are placed at the beginning, followed by complement components.
B. complement components are placed at the beginning, followed with the main components at the end of a sentence.
C. There is no specific order for the main components and complement components.
12. Do you use "I/We think" more often than "it is estimated that..." in your English writing?
A. Yes
B. No
C. Uncertain

13. What is your usual order in depicting events/ incidents?

A. attitudes/ opinions/ conclusions are followed by reasons/ conditions/facts.

B. reasons/ conditions/ facts are followed with attitude/ opinion/ conclusion.

C. Other

14. Are you used to go straight to the point in English writing?

A. Yes. I prefer to get the main idea understood by stating it at the very beginning of an essay.

B. I am not quite used to it. But I will do so when asked.

C. No. I would rather lay the groundwork before putting forth the main idea.

15. Which of the following do you think is more acceptable in English?

A. He had been engaged in a construction job, and after he completed it, he went to Georgia to spend his vacation basking in the Caucasian sun, and flew back just the day before.

B. He had flown in just the day before from Georgia where he had spent his vacation basking in the Caucasian sun after the completion of the construction job he had been engaged in the South.

C. Other

\section{Appendix B}

The following are some of the answers to choice Cs for Items 8, 9 and13.

For Item 8

I miss her name.

I don't know her name.

I cannot keep her name in mind.

\section{For Item 9}

The passage is too difficult for me to understand.

The passage is so difficult that I cannot understand it

For Item 13

It all depends. Sometimes attitudes/ opinions/ conclusions are followed by reasons/ conditions/facts, and 
sometimes reasons/ conditions/ facts are followed with attitude/ opinion/ conclusion.

\section{Copyrights}

Copyright for this article is retained by the author(s), with first publication rights granted to the journal.

This is an open-access article distributed under the terms and conditions of the Creative Commons Attribution license (http://creativecommons.org/licenses/by/3.0/). 